\title{
Kvinner, psykisk helse og suicidalitet
}

\author{
Ved Alexandra Naletova
}

\begin{abstract}
7. nasjonale konferanse om selvmordsforskning og -forebyggning arrangeres i Oslo 4. og 5. april. En av årets sesjoner er avsatt til temaet kvinnehelse i relasjon til suicidalitet. I denne artikkelen gis en kort oppsummering av helseproblemer og suicidalitet i relasjon til kjønn.
\end{abstract}

Verdens psykiaterforening (World Psychiatric Association) utga i september 2005 to viktige dokumenter vedrørende kvinners psykiske helse og vold mot kvinner (International Consensus Statement on Women's Mental Health og Consensus Statement on Interpersonal Violence Against Women (Stewart, 2006)). I dokumentene understreker man at kvinners psykiske helse er avhengig av lik tilgang til grunnleggende rettigheter som autonomi, utdanning, $\varnothing$ konomisk trygghet og helsehjelp. God psykisk helse kan ikke oppnås hvis kvinner er utsatt for diskriminering for kjønn, alder, inntekt, etnisk bakgrunn, seksuell legning eller religiøs tro (Stewart, 2006).

Når man snakker om kjønn og kjønnsrelaterte helseproblemer, bør man ta hensyn både til biologisk kjønn og sosialt konstruert kjønn (eng.: gender). Sosialt konstruert kjønn spiller en viktig rolle med hensyn til kvinners og menns kontroll over sosio $\varnothing$ konomiske forhold, over deres sosiale posisjon og rolle i samfunnet, hvilket igjen avgjør graden av kontroll over psykisk helse og eksponering for risikofaktorer. Men det er samspillet mellom biologisk og sosialt konstruert kjønn som fører til forskjell i risikofaktorer og helses $\varnothing$ kende atferd hos menn og kvinner.

Kvinners reproduktive liv er biologisk determinert, ikke minst på grunn av kjønnshormonfluktuasjon. Flere perioder i kvinners liv, som menarke, premenstruelle perioder, tiden under graviditet og etter f $\varnothing$ dselen og overgangsalder kan $\varnothing$ ke risikoen for å utvikle psykiske problemer. Det har blitt foreslått å kalle helseproblemer som oppstår i bestemte perioder hos kvinner for "sykdommer forbundet med reproduktivt liv" (Reproductive Related Disorders) (Halbreich, 2010). Man kan allikevel ikke entydig konkludere at kvinnelige kjønnshormoner eller endringer i hormonnivåer er direkte årsak til utvikling av psykiske plager hos kvinner. Andre faktorer, som sosiale belastninger og biologisk predisposisjon, må også tas i betraktning.

\section{Kjønnsforskjeller i psykisk helse og suicidalitet}

Forekomsten av alvorlige psykiske lidelser som schizofreni og bipolar lidelse er lik hos begge kjønn. Depresjon, angst, spiseforstyrrelser, PTSD og somatoforme lidelser ser man imidlertid oftere hos kvinner (på verdensbasis), mens menn oftere har avhengighetssykdommer og visse alvorlige personlighetsforstyrrelser. En norsk studie påviste at til sammen $21,5 \%$ av norske kvinner lider av depresjon, angstlidelser (panikkangst, generalisert angst, fobier) og somatoforme lidelser, mens tallet for menn er 11,5\% (Sandanger et al., 1999).

Det er godt kjent at menn oftere enn kvinner d $\varnothing \mathrm{r}$ ved selvmord, mens forekomsten av selvmordsfors $\varnothing \mathrm{k}$ er høyere blant kvinner. Selvmordsraten i Norge var i 2009 19,5 per 100000 for menn og 7,6 per 100000 for kvinner (Statistisk sentralbyrå, 2011, http://www.ssb.no/ emner/03/01/10/dodsarsak/tab-2010-1203-08.html). Denne forskjellen kan muligens forklares med at kvinner s $\varnothing$ ker hjelp oftere enn menn, er mer åpne for å snakke om sine følelser og innehar en viktigere omsorgsrolle i familien. $\AA$ ha barn under 2 år er påvist å være en beskyttende faktor mot selvmord hos kvinner (Qin et al., 2000). Kvinner og menn bruker også forskjellige selvmordsmetoder. Mens flertallet av kvinner velger forgiftning med legemidler og andre substanser, velger flertallet av menn farligere og raskere metoder som hengning og skyting.

\section{Reproduktivt liv og fare for suicidal atferd}

\section{Menarke}

Forekomsten av depresjon er lik hos jenter og gutter $f \varnothing r$ ungdomsalderen. Etter menarke - den første menstruelle blødningen hos en pike - er jenter mer tilbøyelige til å utvikle symptomer på alvorlig depresjon. To tredeler av jentene med depressive plager har komorbide (samtidige) psykiske lidelser, oftest en angstlidelse (Born et al., 2002). Flere studier har vist at tidlig innsettende menarke kan ha sammenheng med utvikling av depresjon og stoffmisbruk (Stice et al., 2001), selvmordsfors $\varnothing \mathrm{k}$ (Wichstrøm, 2000), selvskading og selvmord (Deng et al., 2011).

En rekke studier, blant annet fra Norge (Dieserud et al., 2010) har vist at selvmordsfors $\varnothing \mathrm{k}$ er betydelig hyppigere blant tenåringsjenter enn gutter i samme alder. Jenter rapporterer oftere familieproblemer og sjeldnere psykiske problemer som underliggende årsak til suicidale handlinger sammenliknet med gutter (Dieserud et al., 2010).

\section{Menstruasjonssyklus}

Med menarke begynner menstruasjonen, som karakteriseres ved månedelige sykliske hormonsvininger i kvinnelige kjønnshormonnivåer ( $\varnothing$ strogen og progesteron). Det har vært vanskelig å påvise en klar sammenheng mellom ulike faser av menstruasjonssyklusen og suicidal atferd, men man har konkludert med at ikke-dødelig suicidal atferd oftere oppstår i faser av menstruasjonssyklus når фstrogennivået er lavt, og hos kvinner med premenstruelle plager (Saunders et al., 2006). En nyere studie har påvist at risikoen for suicidal atferd er forh $\varnothing$ yet $i$ perioder der østrogen- og progesteronnivåene er lave (i menstruell fase av menstruasjonssyklus, menopause og amenore) (Baca-Garcia et al., 2010).

Studier om risiko for suicidal atferd hos kvinner med premenstruelle plager har gitt motstridende resultater. Enkelte studier konkluderer med at det ikke er $\varnothing \mathrm{kt}$ forekomst av suicidal atferd i premenstruell uke hos kvinner med PMDD (Premenstrual dysphoric disorder), premenstruell depressiv lidelse, sammenlignet med kvinner uten PMDD (BacaGarcia et al., 2004), mens andre har 

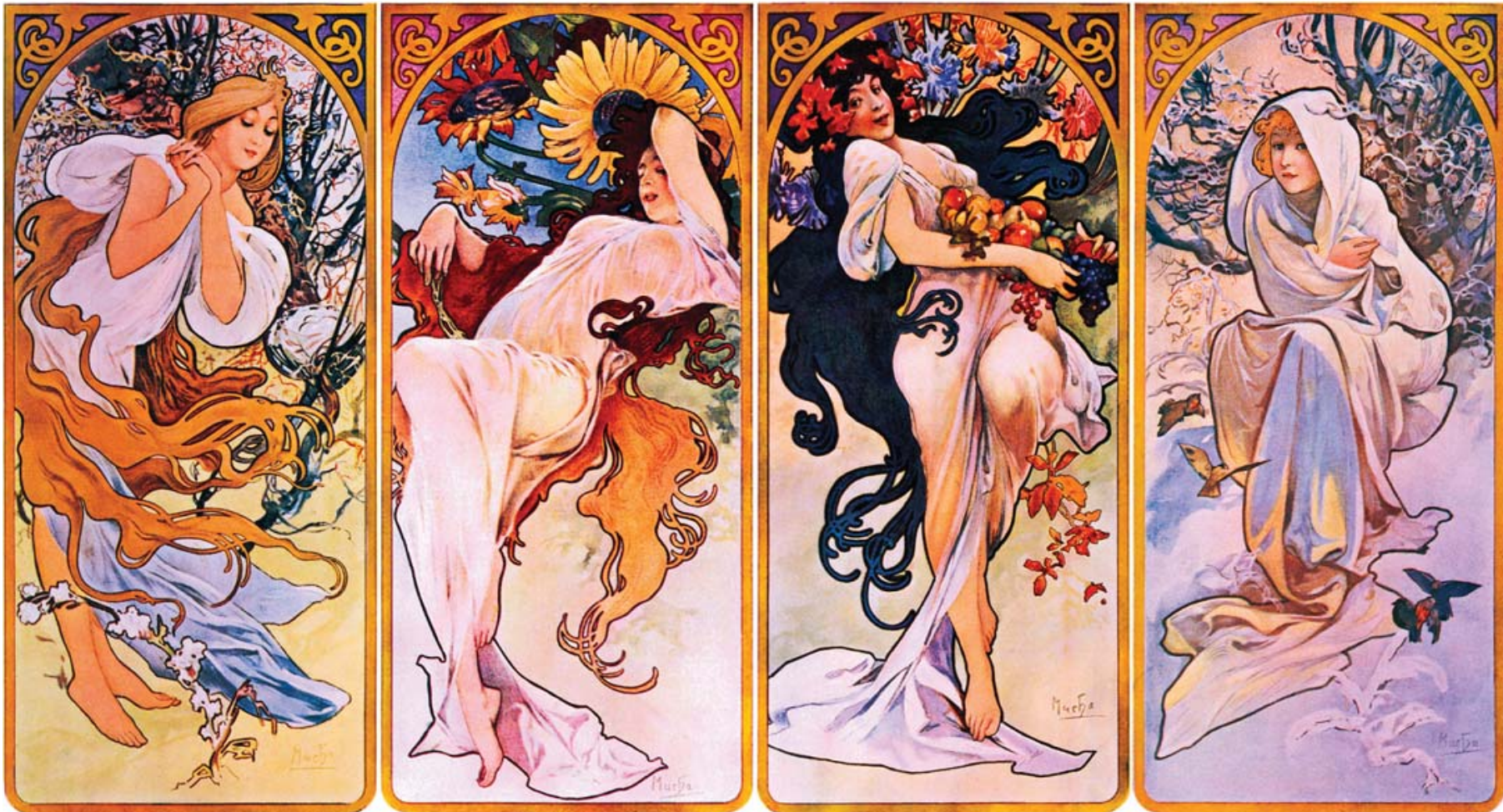

Alphonse Mucha: Les quatre saisons (ca. 1895)

påvist $\varnothing \mathrm{kt}$ risiko for suicidalfors $\varnothing \mathrm{k}$ og moderat $\varnothing \mathrm{kt}$ risiko for suicidaltanker hos kvinner med alvorlige premenstruelle plager (Wittchen et al., 2002).

\section{Perimenopause}

I alderen 45-49 år begynner menstruasjonssyklusen å bli uregelmessig. Man kaller denne perioden for perimenopause. Kvinner har i denne perioden forhøyet risiko for å få depressive plager (Schmidt et al., 2004) (Freeman et al., 2006).

Risikoen for å få selvmordstanker er for kvinner i denne perioden høyere enn for yngre kvinner (i premenopause) og eldre kvinner (i postmenopause). Risikoen for å få selvmordstanker i perimenopause er også høyere enn for menn i alle aldersgrupper og er uavhengig av samtidig tilstedeværende affektive lidelser eller angstlidelser (Usall et al., 2009).

\section{Graviditet, perioden etter} fødsel og fare for suicidal atferd Etter fødselen utvikler noen kvinner postpartum depresjon, postpartum blues ("barseltårer") og postpartum psykoser. Man regner med at ca. 10-20 \% utvikler postpartum depresjon - depressive symptomer som oppstår innen 4 uker (etter DSM-IV-kriterier) eller 6 uker (etter ICD-10-kriterier) etter fødselen. Postpartum blues inkluderer symptomer som mild depresjon, affektlabilitet, tristhet og gråtetokter, oppstår i løpet av 3-5 dager etter fødsel og forsvinner etter 10. dag. Man betrakter postpartum blues som innenfor normalområdet av følelsesmessige reaksjoner etter fødsel.

Selvmordsrisikoen både under svangerskapet og i løpet av det første året etter fødselen er lav, og morsrollen kan anses som en beskyttende faktor (Appleby, 1991). Tallene for postpartum dødsfall forårsaket av selvmord varierer: Lindahl angir at $20 \%$ av alle dødsfall i postpartumperioden har selvmord som årsak (Lindahl et al., 2005), mens Oates angir $28 \%$ (Oates, 2003). Det ser ut til at de fleste av selvmordene foregår i løpet av den første måneden etter $\varnothing \varnothing$ dselen (Appleby, 1991).

Postpartumpsykoser rammer ca. 0,1\% av kvinner, og man tror de representerer en form for bipolar lidelse (Chaudron et al., 2003).
Selvmordsraten ved postpartumpsykose er angitt fra 1,4 \% til 10,9\% i forskjellige studier, men de fleste studier har funnet en selvmordsrate på rundt 4 \% (Pfuhlmann et al., 2002). Selvmordsrisikoen er påvist å være 70 ganger høyere i løpet av det første året etter fødselen for kvinner som hadde postpartum psykose sammenliknet med friske kvinner (Appleby et al., 1998).

\section{Ufrivillig barnløshet, abort og kvinnehelse}

Infertile kvinner har forhøyet risiko for å utvikle angstlidelser og depressive plager (Klemetti et al., 2010). Forekomsten av depresjon og seksuell dysfunksjon er høyere hos ufrivillig barnløse kvinner (Nelson et al., 2008). Samtidig får flere kvinner enn menn alvorlige depressive symptomer etter mislykket behandling for infertilitet (Lund et al., 2009).

Spontanabort kan ha konsekvenser for kvinners psykiske helse. Ca. $40 \%$ av kvinnene opplever sorg kort tid etter spontanabort. Psykiske plager som depresjon og angst kan være til stede i perioden mellom 6 og 12 måneder etter 
spontanabort, og opptil $50 \%$ av kvinnene kan utvikle en alvorlig depresjon (Lok et al., 2007). Tidligere psykiske lidelser og infertilitet, manglende sosialt nettverk og problemer i ekteskapet kan anses som risikofaktorer for utvikling av psykiske plager etter spontanabort (Lok et al., 2007).

Provosert abort er assosiert både med psykiske lidelser som stemningslidelser, angst, rusmisbruk, suicidale tanker og suicidalfors $\varnothing \mathrm{k}$ (Mota et al., 2010). I en registerstudie utført i Finland fant man signifikant forh $\varnothing y e t$ suicidalrate assosiert med spontanabort og provosert abort (Gissler et al., 1996).

\section{Konklusjon}

Flere perioder i løpet av kvinners reproduktive liv er assosiert med en $\varnothing$ kende sårbarhet for å utvikle psykiske plager med følgende risiko for forskjellige former av suicidalitet (suicidale tanker, planer og suicidale handlinger). Kunnskap om dette kan ha betydning særlig for helsepersonell som driver behandling av kvinnelige suicidale pasienter, men også for allmennleger og gynekologer i praktisk og i forebyggende arbeid.

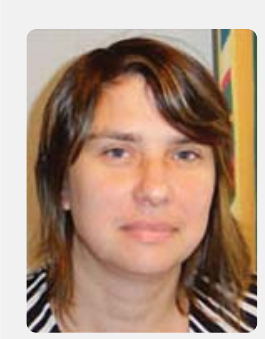

Alexandra Naletova er psykiater og arbeider ved DPS Gjøvik Poliklinikk Toten, samt som stipendiat ved Nasjonalt senter for selvmordsforskning og -forebygging. Hennes forskning fokuserer på sårbarhetsfaktorer for suicidalitet knyttet til menstruasjonssyklus.

\section{Referanser}

Appleby, L. (1991). Suicide during pregnancy and in the first postnatal year. BMJ, 302, 137-140.

Appleby, L., Mortensen, P. B., \& Faragher, E. B. (1998). Suicide and other causes of mortality after post-partum psychiatric admission. Br.J.Psychiatry, 173, 209-211.

Baca-Garcia, E., Diaz-Sastre, C., Ceverino, A., Garcia, R. E., Oquendo, M. A., Saiz-Ruiz, J. et al. (2004). Premenstrual symptoms and luteal suicide attempts. Eur.Arch.Psychiatry Clin. Neurosci., 254, 326-329.
Baca-Garcia, E., Diaz-Sastre, C., Ceverino, A. Perez-Rodriguez, M. M., Navarro-Jimenez, R., Lopez-Castroman, J. et al. (2010). Suicide attempts among women during low estradiol/low progesterone states. J.Psychiatr.Res., 44, 209-214.

Born, L., Shea, A., \& Steiner, M. (2002). The roots of depression in adolescent girls: is menarche the key? Curr.Psychiatry Rep., 4, 449-460. Chaudron, L. H. \& Pies, R. W. (2003). The relationship between postpartum psychosis and bipolar disorder: a review. J.Clin.Psychiatry, 64, 1284-1292.

Deng, F., Tao, F. B., Wan, Y. H., Hao, J. H., Su, P. Y., \& Cao, Y. X. (2011). Early menarche and psychopathological symptoms in young chinese women. J.Womens Health (Larchmt.), 20, 207-213.

Dieserud, G., Gerhardsen, R. M., Van den Weghe, H., \& Corbett, K. (2010). Adolescent suicide attempts in Baerum, Norway, 1984-2006. Crisis, 31, 255-264.

Fido, A. \& Zahid, M. A. (2004). Coping with infertility among Kuwaiti women: cultural perspectives. Int.J.Soc.Psychiatry, 50, 294-300.

Freeman, E. W., Sammel, M. D., Lin, H., \& Nelson, D. B. (2006). Associations of hormones and menopausal status with depressed mood in women with no history of depression.

Arch.Gen.Psychiatry, 63, 375-382.

Gissler, M., Hemminki, E., \& Lonnqvist, J. (1996). Suicides after pregnancy in Finland, 1987-94: register linkage study. BMJ, 313, 1431-1434.

Halbreich, U. (2010). Women's reproductive related disorders (RRDs). J.Affect.Disord., 122, $10-13$.

Klemetti, R., Raitanen, J., Sihvo, S., Saarni, S.\& Koponen, P. (2010). Infertility, mental disorders and well-being - a nationwide survey. Acta Obstet.Gynecol.Scand., 89, 677-682.

Lindahl, V., Pearson, J. L., \& Colpe, L. (2005). Prevalence of suicidality during pregnancy and the postpartum. Arch.Womens Ment.Health, 8, $77-87$.

Lok, I. H. \& Neugebauer, R. (2007). Psychological morbidity following miscarriage. Best.Pract.Res. Clin.Obstet.Gynaecol., 21, 229-247.

Lund, R., Sejbaek, C. S., Christensen, U., \& Schmidt, L. (2009). The impact of social relations on the incidence of severe depressive symptoms among infertile women and men. Hum.Reprod., 24, 2810-2820.

Mota, N. P., Burnett, M., \& Sareen, J. (2010). Associations between abortion, mental disorders, and suicidal behaviour in a nationally representative sample. Can.J.Psychiatry, 55, 239-247.

Nelson, C. J., Shindel, A. W., Naughton, C. K., Ohebshalom, M., \& Mulhall, J. P. (2008). Prevalence and predictors of sexual problems, relationship stress, and depression in female partners of infertile couples. J.Sex Med., 5, 1907-1914.
Oates, M. (2003). Perinatal psychiatric disorders: a leading cause of maternal morbidity and mortality. Br.Med.Bull., 67, 219-229.

Pfuhlmann, B., Stoeber, G., \& Beckmann, H. (2002). Postpartum psychoses: prognosis, risk factors, and treatment. Curr.Psychiatry Rep., 4, 185-190

Qin, P., Agerbo, E., Westergard-Nielsen, N., Eriksson, T., \& Mortensen, P. B. (2000). Gender differences in risk factors for suicide in Denmark. Br.J.Psychiatry, 177, 546-550.

Sandanger, I., Nygard, J. F., Ingebrigtsen, G., Sorensen, T., \& Dalgard, O. S. (1999). Prevalence, incidence and age at onset of psychiatric disorders in Norway. Soc.Psychiatry Psychiatr.Epidemiol., 34, 570-579.

Saunders, K. E. \& Hawton, K. (2006). Suicidal behaviour and the menstrual cycle. Psychol.Med. 36, 901-912.

Schmidt, P. J., Haq, N., \& Rubinow, D. R. (2004) A longitudinal evaluation of the relationship between reproductive status and mood in perimenopausal women. Am.J.Psychiatry, 161, 2238-2244

Sein, A. J., Chodorowski, Z., Ciechanowicz, R., Klimaszyk, D., \& Lukasik-Glebocka, M. (2005) Acute suicidal self-poisonings during pregnancy. Przegl.Lek., 62, 434-435.

Stewart, D. E. (2006). The International Consensus Statement on Women's Mental Health and the WPA Consensus Statement on Interpersonal Violence against Women. World Psychiatry, 5, 61-64.

Stice, E., Presnell, K., \& Bearman, S. K. (2001). Relation of early menarche to depression, eating disorders, substance abuse, and comorbid psychopathology among adolescent girls. Dev.Psychol. $37,608-619$.

Usall, J., Pinto-Meza, A., Fernandez, A., de, G. R., Demyttenaere, K., Alonso, J. et al. (2009). Suicide ideation across reproductive life cycle of women. Results from a European epidemiological study. J.Affect.Disord., 116, 144-147.

Wichstrom, L. (2000). Predictors of adolescent suicide attempts: a nationally representative longitudinal study of Norwegian adolescents. J.Am.Acad.Child Adolesc.Psychiatry, 39, 603-610.

Wittchen, H. U., Becker, E., Lieb, R., \& Krause, P. (2002). Prevalence, incidence and stability of premenstrual dysphoric disorder in the community. Psychol.Med., 32, 119-132. 